\title{
Parsing decomposable idioms
}

\author{
Ingrid Fischer and Martina Keil \\ IMMDII, University of Erlangen \\ Martensstr. 3 \\ 91058 Erlangen, Germany \\ \{idfische,keil\}@informatik.uni-erlangen.de
}

\begin{abstract}
Verbal idioms can be divided into two main groups: non-compositional idioms as kick the bucket and compositional/decomposable idioms as spill the beans. In the following we will point to the fact that there are German decomposable idioms which can be decomposed into components, having identifiable meanings contributing to the meaning of the whole. These idiom components are taken to have referents. Taking these facts into account we propose an adequate way to represent the idiomatic meaning by Kamp's Discourse Representation Theory (DRT). Furthermore, we show how to parse idiomatic sentences and how to process the proposed semantic representation. While parsing idioms, the necessary idiomatic knowledge of the idioms' syntax and semantics is extracted from a special idiomatic knowledge base called PIIRAsho Lit.
\end{abstract}

\section{Introduction}

Today it becomes more and more evident that a too restricted view on idiomatic phenomena is of limited use for the purpose of natural language processing. Therefore, it is now widely accepted that we have to distinguish at least two groups of figurative verbal phrasal idioms: first, there is a group of syntactically frozen idioms as kick the bucket, meaning "die", which are called noncompositional. Second, there is a group which shows more syntactic and semantic flexibility. An example for the latter group, often called compositional or decomposable $e^{1}$ idioms, is spill the beans

\footnotetext{
${ }^{1}$ By classfying idioms with the terms compositional respectively decomposable the same property is decribed by two different point of views. The first notion is a more structural term, the second notion a more process-oriented term. See (Geeraerts, 1992).
}

meaning "divulge information". With this group we are dealing here in depth. In this paper we propose an adequate semantic representation for idiomatic knowledge and show a way of processing syntax and semantics of decomposable idioms.

In the following we will first deal with the idea of decomposability of idioms in section 2 . In section 3 we will present our proposal of an adequate representation of the idioms' meaning by means of DRT. Before we will outline a way of processing decomposable idioms in section 5 , we will briefly introduce the necessary tools for the parsing process in a few bricf words in section 4 . Finally, in section 6 we show some possible extensions.

\section{Decomposable idioms and the referential status of their idiom chunks}

In contrast to non-compositional idioms, decomposable idioms are able to undergo several syntactic operations that lead to the opinion that "pieces of an idiom typically have identifiable meanings which combinc to produce the meaning of the whole" (Wasow, 1982).

As example, we consider the syntactic behavior of the German verbal idioms einen Bock schießen (lit.: "shoot a buck", fig.: "make a mistake", fig. eq.: "make a bloomer") $)^{2}$ and $j m d m$. einen Bären aufbinden (lit.: "tie sb. a bear on", fig.: "tell a tall tale to sb.", fig. eq.: "pull sb.'s leg"; "spin sb. a yarn")

In the following examples several modifications

\footnotetext{
${ }^{2}$ Since a high degree of language competence is necessary when judging about grammaticality of idiom constructions, we - as German native speakers - choose German idioms as examples. We establish the following convention for translation: literal: literal English word-by word translation of the German idiom; figurative: English paraphrase of the figurative meaning; fig. equivalent: English idioms with an equivalent meaning.
} 


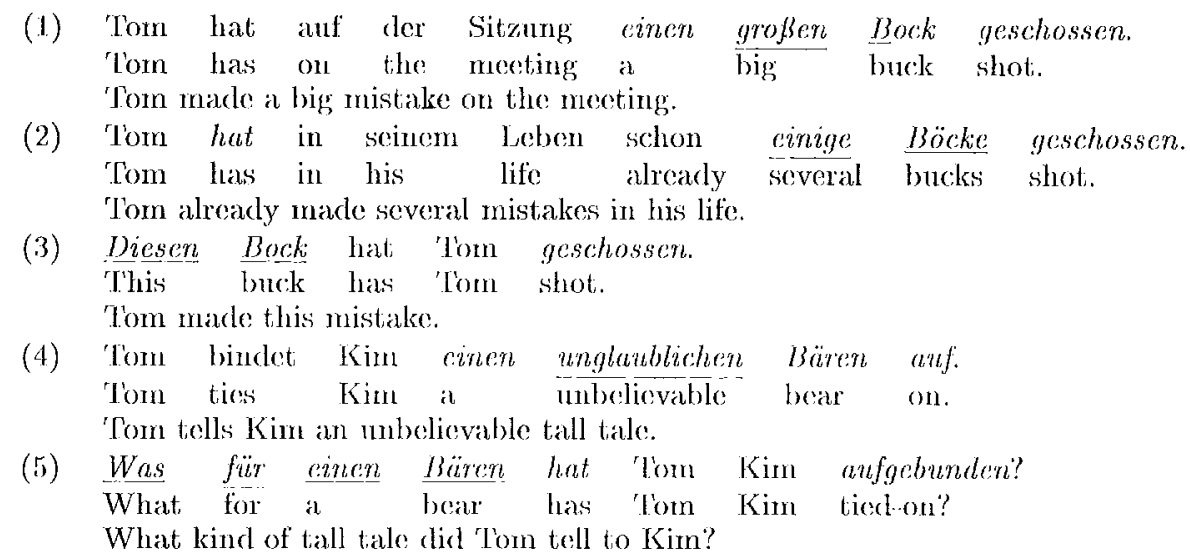

can be found: adjectival modifications in $(1,4)$, quantification in (2), and focussing by domonstrative determiner (3) and by (question in (5) apply to the idioms internal NPs. It is importiant to notice? that these oporations and modifications in (1) (5) are not result of puns or: word plays but grammatically and stylistically ummarked constructions.

Similas examples can bo found in other langlages, too. 'The first German example has a Dutch equivalont: cen bok schieten, where internal modifications and quantification are possible. A french decomposable idiom is lever un lisure (lit.: "raise a hare", fig.: "touch a clelicato subjoct."); prendere una cantonata (lit.:"take a cornor") meaning "to mako a mistake" is an itialian one. Therefore, internal modifialsility of idioms secms not to be restricted on the German language.

\subsection{Decomposable idioms are structured entities}

It; is evident that a component like bucket of a non compositional idiom as kick the bucket cannot undergo such kind of syntactic operations. Therefore, the moaning of non compositional idioms is seen as an unstructured complex. Components like bucket which do not carry any individual meaning are called quasi-arguments with a non referential function (Chomsky, 1981). In opposite to this, components of decomposable idioms do carry some individual meaning! "Of course, these meanings aro not the literal meanings of the parts" is stated in (Wasow, 1982). Then, the questions arise, which kind of meaning do these parts carry? Which is the hidden semantic stuff of Bock or Bär respectively, that is modified, inquired, quantified, and emphasized?

We adopt the point of view that items as Bock or Bär cannot be considered as quasi-arguments but as figurative arguments. Furthermore, wo fol- low the opinion that such idiomatic strings are not unstructured complexes, but structiuced entities. Their structuring takes place in parallol to the structuring of the literally interpreted slring (Burger, 1973). Our intuition suggests to paraphrase einen Bock schießen by "einen Fehler machon" (lit.: "make a mistake") and jmdm. einen Bären aufbinden by "jmelm. cine Lïgengeschichte crzählen", (lit.: "tcll a tall tale to sb."). It is evident for the paraphluase and the icliom to have at least the same syntactic structure as shown in the next tible.

\begin{tabular}{|l||l|l|}
\hline eincm & Bock & $\begin{array}{l}\text { schickon } \\
\text { shoot }\end{array}$ \\
\hline bunch & Fohler & machen \\
\hline$a$ & mistake & make \\
\hline
\end{tabular}

\begin{tabular}{|c|c|c|c|}
\hline $\begin{array}{l}\text { jindin. } \\
\text { to } s b \text {. }\end{array}$ & einen & $\begin{array}{l}\text { Bü̈ren } \\
\text { bear }\end{array}$ & $\begin{array}{l}\text { aufbinden } \\
\text { tie-on }\end{array}$ \\
\hline $\begin{array}{l}\text { jindm. } \\
\text { to sb. }\end{array}$ & sine & $\begin{array}{l}\text { Lifigengeschichte } \\
\text { tall tale }\end{array}$ & $\begin{array}{l}\text { erzatilen } \\
\text { tell }\end{array}$ \\
\hline
\end{tabular}

In addition it is important, that also tho semanlics of the paraphrase and the idiom can be struclured in parallol.

\subsection{Figurative referents of idiom chunks}

'Lo explain this, let $1 \mathrm{~s}$ now consider the problem from the referential point of view. We claim that inclividual componentis of decomposable idioms an be considered digurative arguments and that these figurative arguments have referents on their own.

Following (Nunberg, 1978) who first discussed the referential aspece of idioms let "1w consider that verb phrases 'refer' to states and activities, and transitive verb phrases normally refor to states and activities that are bost identified as 'open relations' of the form $R x b$ where ' $R$ ' stiands for the rolation referred to by the verb, ' $x$ ' is a variable for the referent of the sentence subject, and ' $b$ ' stands for the reforent of the object NP." 
(6) $\left[\begin{array}{l}x y z \\ \operatorname{Kim}(x) \\ \operatorname{Tom}(y) \\ \operatorname{bear}(z) \\ \operatorname{incredible}(z) \\ \operatorname{tie-on}(x, y, z)\end{array}\right.$

(7)

$x y$
$\operatorname{Kim}(x)$
$\operatorname{Tom}(y)$
incredible(?)
lie-to(x,y)

(8)

\begin{tabular}{|l|}
\hline$x y v u u$ \\
Kim $(x)$ \\
Tom $(y)$ \\
incredible(?) \\
lic-to $(x, y)$ \\
$v=x$ \\
$w=y$ \\
tall-tale $(u)$ \\
believe $(w, v, u)$ \\
$\mathbf{u}=?$ \\
\hline
\end{tabular}

$x y z u v w$

$\operatorname{Kim}(x)$

$\operatorname{Tom}(y)$

incredible $(z)$

(10)

tall-tale $(z)$

$\operatorname{tell}(x, y, z)$

$v=x$

$w=y$

$u=z$

belicve $(w, v, u)$
On this basis, an idiom is called decomposable because the situation to which it refers can be seen as an open relation $R x b$.

For the idiom einen Bock schiefen this means that schießen is a two argument relation with a variable for the subject NP, the noun phrase einen Bock referring to the concept a mistake and the verb schießen denoting a situation where someone is acting. Extending this idea to the decomposable idiom $j m d m$. einen Bären aufbinden, it is necessary to suppose a three-argument--relation $R x y b$ with two open variables: $x$ represents the subject NP and $y$ the indirect object NP. The idiom $j m d m$. einen Bären aufbinden is now decomposable into the noun phrase einen Bären, referring to a tall tale, and the verb aufbinden, referring to the activity of telling.

By paraphrasing decomposable idioms, the identifiable parts of meaning are taken into account. That means that, the concept of the underlying referent, which often may be an abstract entity lacking a physical extension, should be verbalized and included into the paraphrase.

Notice that in the above cases the relation between the idiom components Bock, Bär and its paraphrased referents Fehler, Lügengeschichte is not a metaphorical one, but a conventional one. There are also decomposable idioms where decomposability is based on metaphoriocal knowledge.

Besides our introspective intuition, ovidence for the proposed paraphrases is found through text analyses. The strongest support comes from the everyday usage of language being observed for example in textcorpora with newspapers, literature etc. (Keil, 1995).

\section{Semantic representation of decomposable idioms via DRT}

In the following, we will point out the problematic nature of meaning representation of idiomatic language with the help of DRT (Kamp, 1993). We will show the arvantages of our theoretical considerations above, that can be best illustrated by DRT already including mechanisms to handle ref- crents.

Consider example (4) Kim bindet Tom einen unglaublichen Bären auf (fig.: "Kim tells Tom an incredible tall tale"). DRS (6) shows the result of processing the -- in this case senseless -.. litcral reading of sentence (4) without any idiom handling procedures. ${ }^{3}$ DRS (7) represents a non compositional solution: after analysing the structure syntactically, the literal meaning of the multiword lexeme $j m d m$. einen Bären aufbinden is substituted by the "complex meaning" of the simple verb phrase as "jmdn. belügen" ("lie to sb."). Note that it is now a problem to represent the internal adjectival modifier incredible correctly. There is no discourse referent for that the condition incredible as semantic representation of the adjective unglaublich holds. Furthermore, if we want to represent the sentence $\operatorname{Er}$ glaubte $i h r$ die Lügengeschichte ("He believes her the tall tale") - continuing example (4) - , the connection of the discourse referents cannot be made correctly as shown in DRS (8). The connection of the resumed constituent einen unglaublichen Bären and the resuming definite description die unglaubliche lügengeschichte, which dofinitively exists, cannot be mapped into the DRS.

We claim that a more appropriate semantic representation of this idiom should respect its kind of composition and take its referents into consideration. On the base of the discussed paraphrase "eine Lügcngeschichte erzählen", we offer the solution shown in (9). This representation now includes the condition incredible $(z)$, tall$\operatorname{talc}(z), \operatorname{tell}(x, y, z)$ to represent the idiom. In (10) the continuation of our sentence is shown. Refercrice identity between bear and tall-tale is established by the cquation $u=z$.

What decomposable idioms concerns, now the

\footnotetext{
${ }^{3}$ For the reason of simplification, we choose English predicate names for the conditions in the DRSs, c.g. instead of logical clauses as bär(x), aufbinden $(x, y, z)$, or belügen $(x, y)$ we present the sentence meaning with bear $(x)$, tie-on $(x, y, z)$, or lie-to $(x, y)$. This way the expenditure of translation can be reduced in this paper.
} 
base for adequate anaphora resolution and resolution of definite descriptions resuming carlier introduced discourse material is created.

\section{Used Tools: The Basic Parser and the Lexicon}

In the following we introduce the tools we have used for parsing idiomatic sentences. We give a short description of the underlying chart- parsingsystem (Fischer, 1995) and our idiomatic lexical database, called Prirasso--Lex, that wo use in the sense of an additional idiom list proposed by (Weinreich, 1969).

'The design of our parsing system was governed by two main goals: parallelism and incrementality. Nevertheless different formalisms are used to represent syntactic and semantic features, having the advantage that for syntax as well as for scmantics the most appropriate formalism can be chosen. ${ }^{4}$ Consequently, to guarantee parallelism, this also requires a connection mechanism between these formalisms is necessary. In the following sections the structure of the parser will be doscribed along these lines.

The grammar formalism of our system is an extension of the well known PA'TR-II. Syntac:tic information is encoded in feature structures. With the help of constraint equations these feature structures can be modified. The underlying unification mechanism is enriched with sequences as well as simple value disjunctions.

For our application the semantic formalism is of more interest. We decided to adopt l'inkal's approach (Bos, 1996) of J)R'T. In contrast to Kamp DRSs are not constructed in a top down fashion from a phrase structure tree, but bottom-11) using a version of $\lambda$ calculus. When combining $\lambda$ calculus and JPRT, two different kinds of abstraction are possible. First one can abstract over a complete DRS (partial DRS') or one can abstract only over a single discourse referent (predicative DRSS). The following example shows both kind of abstraction with the $\lambda$-I)RS for the inclefinite determiner and the noun mistake.

$$
\begin{array}{ll}
\lambda Q \lambda R & x]+Q(\mathrm{x})+\mathrm{R}(\mathrm{x}) \quad \lambda x[\operatorname{mistake}(x) \\
\hline
\end{array}
$$

Foature structures are used to encole the $\lambda$-I)]RSs. The main operation on $\lambda$-DRSs is tho functional

\footnotetext{
${ }^{4}$ This is the so called co-descriptive approach. Using lhe sane formalism for syntactic: and semantic: construction is called the integrated approach, in the descriptive approach they are build up sequentially.

${ }^{5}+$ indicates the union of DRSs.
}

compostion on a partial DRS as functor and a predicative DRS as argument. It is implemented with the holp of unification on the feature structures.

Our parsing engine is an active chart parser. The chart edges are marked, as usual, with category symbols. Additionally, syntactic feature structures and $\lambda$ DRSs are attached to every edge. For the extension of active edges according to the fundamental rule of active chart parsing, all syntactic and semantic constraints of the respective grammar rule must bo satisfied.

A grammar rule consists of three parts: Context free rules over category symbols consti tute the backbone of every grammar. They are annotated with equations, the solutions of which result in syntactic feature structures. In these equations the category symbols are used as projections to mark the structures to be used. The category symbols are also used in the semantic operations on DRSS. For semantics, besides an operator compose for functional composition, an operator id for identity is used.

An interface module helps to connect different lexicons to the parser. At the moment, a syntactic lexicon containing foatiure structures, a semantic lexicon with $\lambda$-DIRSs and a special loxicon for idioms, callod PhInsko-Lex (Keil, 1994), (Koil, 1995) are connected to the parser.

Phraseo-Lex is a computational lexicon which was specially developed for idiomatic knowledge. Of all diversed syntactic, semantic, and pragmatic information provided by P'IRASH,O-LLX, we only need for our purpose lommatia, base lexemes, (idiom participating lexical words: Bock, schießen), the internal syntactic structure encoded as a syntactic tree, the intemal semantic structure encoded as predicate-argument--structure and the logical form.

As example, we show the lexical entrics of our lirst examplary docomposable idiom.

lomma: einen Bock schießen

base lexemes: Bock, schießen

internal syntactic structure: (vpl1

(np-acc (det einen)

(n Bock))

(v schießen))

internal semantic structure:

\begin{tabular}{|c|c|c|}
\hline Íliom & & Paraphrase \\
\hline subject & & subject \\
\hline$\ddot{X}$ & $\rightarrow$ & $\ddot{X}$ \\
\hline $\begin{array}{l}\text { direct objoct } \\
\text { einen Bock }\end{array}$ & $\rightarrow$ & $\begin{array}{l}\text { direct object } \\
\text { a mistake }\end{array}$ \\
\hline $\begin{array}{l}\text { predicate } \\
\text { schießen }\end{array}$ & $\rightarrow$ & $\begin{array}{l}\text { predicate } \\
\text { make }\end{array}$ \\
\hline
\end{tabular}

logical form: make $(x, y)$, mistake $(y)$ 
During the parsing process this necessary idiomatic information is extracted from PHRASEOLEX and mapped into feature structures the parser can handle.

\section{Processing decomposable idioms}

When parsing decomposable idioms with the parser described in the previous section, the following steps are taken:

While initializing the chart, it is important to control whether potential parts of an idiom are found or not. For every word of a sentecne to be parsed it is checked if it is a base lexeme of an idiom. If this test was positive, an additional chart cdge is inserted for cvery idiom the word can occur in. This edge is marked as usual, but with the syntactic feature structure and the $\lambda$-DRS built from the idiomatic information of PIRASFO-LFX.

The feature structure of this idiom edge contains information about how the idiom has to be completed and its underlying syntactic structure. This information is extracted from the PHRASEOLFX syntax- tree. The following examples show the feature structures of schießen and Bock of our running example.

$$
\left.\begin{array}{l}
{\left[\begin{array}{l}
\text { agrm: }\left[\begin{array}{l}
\text { case: nominative } \\
\text { number:singular } \\
\text { person: two }
\end{array}\right] \\
\text { stem: schießen_vpl13 }
\end{array}\right]} \\
\text { val: }\left[\begin{array}{l}
\text { head: }\left[\begin{array}{l}
\text { stem: bock_vpl13 } \\
\text { case: accusative }
\end{array}\right] \\
\text { rest: nil }
\end{array}\right]
\end{array}\right]
$$

The features val (for valency) respcctively $v p l$ (for verbal phraseologism) contain the information necessary to find other relevant parts for building the idiom. While in the case of verbs the feature val just contains more information than usual, namely the stems of the missing parts of the idiom, the feature $v p l$ is used to mark idiomatic information in other syntactic feature structures. Every part of the idiom is marked with an extra ending, in our example _vpl13. This is due to the fact that the same words can occur in different idioms and should not be mixed up during parsing, because of the corresponding semantic structures.
For example, the words Katze and Sack occur as well in die Katze aus dem Sack lassen (fig. eq. "let the cat out of the bag") as in die Katze im Sack kaufen (fig. eq. "buy a pig in the poke").

'The $\lambda$-DRS of the idiomatic edge already contains the literal referent of the part of the idiom they represent. This means the semantic entry for schießen as part of einen Bock schießen already contains the predicate make $(x, y)$.

$$
\lambda x \lambda y \longdiv { \operatorname { m a k e } ( x , y ) }
$$

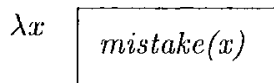

For the same reasons the $\lambda$.DRS for bock contains the predicate mistake $(x)$. This information is taken from the internal semantic structure of the idiom encoded in PHRAseo-Lex as shown above and translated into the $\lambda$-DRS.

It is important to notice that the information concerning decomposable idioms is distributed among all its base lexemes. Nevertheless, we only have one cntry for cvery idiom in our idiomatic. database. Only when initializing the chart, this information is spread over several edges.

In the grammar, special rules must be written to handle the idiomatic edges. In these rules it must be checked whether a complete idiom can be constructed. This is done with the help of extra equations over the special features val and $v p l$ of the idiomatic feature structures. The following example shows a rulc connecting an object and the verb phrase of a sentence, checking if both tho verb and the noun are parts of the same idiom. ${ }^{6}$

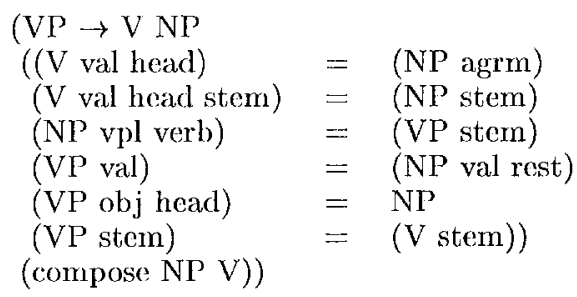

No changes were necessary neither to the chart parser itself nor to the fundamental rule. All features concerning idioms are handled in the lexicons or the grammar.

The result of the parsing process are two readings of the sentence: the literal one, and the idiomatic one. The syntactic feature structures of the literal and the idiomatic reading are the same, as there is no pure syntactic difference between tho two readings. Only the semantic structures differ: one DRS represents the literal idiomatic and one the idiomatic reading.

\footnotetext{
${ }^{6}$ Feature structures and rules are reduced to a minimum in our examples to kecp the structures clear.
} 
This technique allows us to parse sentences like (1) (5) where one part of the idiom is modified and not the idiom as whole. A discourse reforent for bär or bock respectively tall tale or mistake is already introduced cluring the initialization of the chart. This referent can serve as an anchor for an possible adjectival modificr as unglaublich. With the help of the rule connecting adjectives and nouns (not especially written for iclioms!), the predicates incredible (z) and tall-tale (z) are inserted in the DRS. This approach also works for anaphoras. The discourse referent introduced for $B$ "ar is the antecedent for the anapher in the next sentence. 7

\section{Extensions}

It is quite simple to add the processing of noncompositional idioms to our parscr. In this case, the whole literal meaning is bound to the main part of the idiom, in most cases the verb. The semantic of all the other parts is considered cmpty, the cmpty $\lambda$-DRS is bound to the corresponding edges. When parsing a sentence where a part of a non-compositional idiom is modified, the corresponding rules fail, because no discourse referent can be found this modification may be bound to. The only result will bo the literal meaning of the sentence.

Our system starts processing a potential idiom as soon as one base lexeme was found. An improved version of our approach will handle an idiom after some more base lexemes appeared. 'This will reduce the number of lexical lookups to PHRAswo-LFX as well as the number of edges in the parser.

\section{References}

Bos, Johan; Gambäck, Björn; lieskc, Christian; Mori, Yoshiki; Pinkal, Manfred and Worm, Karsten. 1996 Compositional Semantics in Verbmobil, in this volume.

Burger, Harald. 1973 Idiomatik des Deutschen. 'Tübingen.

Chomsky, Noam. 1981. Lectures on Government and Binding: The Pisa lectures. Dordrecht/NL.

Fischer, Ingrid; Geistert, Bernd and Görz, Günther. 1995. Chart-based Incremental Semantics Construction with Anaphora Resolution Using $\lambda$-DRT.

\footnotetext{
${ }^{7}$ Similar results can be found in (Stock, 1989) where Italian idioms are the base. Here the mapping of parts of the idiom to parts of the paraphrase is done with the help of special referent substitutions between the literal and paraphrased meaning. Unfortunately, it is not described in detail how their mechanism would work for anaphoras or modifications of parts of the idiom.
}

In Procedings of the fourth International Workshop on Parsing Technologies, Prag and Karlsbad: 87 88.

Gecraerts, Dirk. 1992 Specialisation and Reinterpretation in Idions. In M. Everacrt, E.-J. van der Linden, A. Schonk, R. Schreuder (eds), Proceedings of IDIOMS. International Conference on Idioms, 'lilburg/NL: 3952.

Kamp, Ians and Reyle, Uwo, 1993 From Discourse to logic. Kluwer Acardernic Press.

Keil, Martina. 1994 Systematische Repräsentation verbalor Phraseologismen und deren Eigenschaften im Lexilkon. In Trost, Harald. (ed.) Proceedings of KONVENS'94, Springer, Wien/Austria: 181-190.

Keil, Martina. 1995 Modell zur Repräsentation verbaler Phrascologismen (Phraseo-Lex). PhD thesis, University of Erlangen-Nuremberg.

Nunberg, Geoffrey D. 1978 The Pragmatics of Reference. Phl thesis. Reproduced by the Indiana University Linguistics Club, Bloomington.

Nunberg, Geoflrey D., Ivan A. Sag, Thomas Wasow. 1994 Idioms. 'Technical report, University of Stanford.

I'ulman, Stephen G. 1993. The Recognition, Interpretation of Idioms In M. Everaert, M, E.-J. Van der Linden (eds.) Proccedings of the first Tilburg Workshop on Idioms, Tilburg/NL: 249-270.

Stock, O. 1989 Parsing with flexiblity, clynamic strategies, idioms in mind. In Computational linguistics, $15,1: 118$

Wasow, Thomas, Ivan A. Sag, and Geoffrey Nunberg. 1982 Idlioms. An Interim Report. In S. Hattori, I. Kazuko, (eds.) Proceedings of the XIIth international congress of linguists, Tokio: 102-115.

Weinreich, Uriel. 1969 Problems in analysis of Idioms. In J. P'uhvel (ed.) Substance and Structure of language, Berkoley, University of California Press: 23 81. 